\section{Breast dose matters}

This high quality meta-analysis by Tromeur et al. ${ }^{1}$ imparts great additional value to the recent Cochrane review on this topic of the evaluation of pulmonary embolism in pregnancy. ${ }^{2}$ Specifically, it is quite impressive that both computed tomography pulmonary angiography (CTPA) and ventilation-perfusion (VQ) imaging have a pooled negative predictive value of $100 \%$ and the pooled rates on non-diagnostic results are comparable in this population.

We however differ regarding the maternal breast radiation exposure. There is an error in referencing Mitchell et al. ${ }^{3}$ in Table 4: the paper does not state the maternal effective doses at all for pregnant patients and the mean breast effective doses are incorrect. Mitchell et al. ${ }^{3}$ were able to reduce the mean breast dose from $7.64 \mathrm{mGy}$ to $3.65 \mathrm{mGy}$ utilizing a reduced $80 \mathrm{kV}$ monitoring scan prior to the diagnostic scan. This paper does not give a dose range, thus approximately $50 \%$ of pregnant patients' breast dose was more than $3.65 \mathrm{mGy}^{3}$ Low-dose perfusion imaging as described by Tromeur et al. ${ }^{1}$ utilizes $25 \%$ of a conventional perfusion dose, thus imparts $25 \%$ of the radiation to the maternal breast, maternal whole body and fetus: $0.16 \mathrm{mGy}, 0.47 \mathrm{mGy}$ and $0.02 \mathrm{mGy}$ respectively. ${ }^{4}$ The CTPA maternal breast dose is at least 22 times higher than that of low dose perfusion imaging, and this is not insignificant given the increased breast mitotic rate during pregnancy. It is interesting that the short term breast cancer rate was not increased post CTPA. However, the majority of the CTPA patients were postpartum when the mitotic rate is normal, while the majority of patients who underwent $\mathrm{VQ}$ imaging were pregnant when the mitotic rate is increased. ${ }^{5,6}$ Limiting detection, screening has not yet begun for these cohorts.

We agree that the fetal dose of both CTPA and VQ are negligible, but given the at least 22-fold increase in breast dose for CTPA, low-dose perfusion imaging is preferred in the setting of a normal chest radiograph.
Renee M. Moadel, Jean-Ju Sheen, ${ }^{2}$

Leonard M. Freeman ${ }^{1}$ and Linda Broyde-Haramati ${ }^{1}$

'Montefiore Medical Center, Albert Einstein College of Medicine, Department of Radiology and ${ }^{2}$ Columbia University, Department of

Obstetrics and Gynecology, New York, NY, USA.

Correspondence: RENEE M. MOADEL

rmoadel@montefiore.org

doi:10.3324/haematol.2019.219584

Disclosures: $L B H$ is the spouse of a board member of Kryon, and $L M F$ is on the advisory panel for Jubilant Draximage.

Contributions: all authors contributed to manuscript preparation.

\section{References}

1. Tromeur C, van der Pol LM, Le Roux PY, et al. Computed tomography pulmonary angiography versus ventilation-perfusion lung scanning for diagnosing pulmonary embolism during pregnancy: a systematic review and meta-analysis. Haematologica. 2019;104(1):176188.

2. van Mens TE, Scheres LJ, de Jong PG, Leeflang MM, Nijkeuter M, Middeldorp S. Imaging for the exclusion of pulmonary embolism in pregnancy. Cochrane Database Syst Rev. 2017;1:CD011053.

3. Mitchell DP, Rowan M, Loughman E, Ridge CA, MacMahon PJ. Contrast monitoring techniques in CT pulmonary angiography: an important and underappreciated contributor to breast dose. Eur J Radiol. 2017;86:184-189.

4. Sheen JJ, Haramati LB, Natenzon A, et al. Performance of low-dose perfusion scintigraphy and CT pulmonary angiography for pulmonary embolism in pregnancy. Chest. 2018;153(1):152-160.

5. Battersby S, Anderson TJ. Proliferative and secretory activity in the pregnant and lactating human breast. Virchows Archiv A Pathol Anat Histopathol. 1988;413(3):189-196.

6. Burton KR, Park AL, Fralick M, Ray JG. Risk of early-onset breast cancer among women exposed to thoracic computed tomography in pregnancy or early postpartum. JThromb Haemost. 2018;16(5):876885. 